Aim of the study: Melatonin (MLT) is reported to exert uroprotective effect due to its antioxidant/anti-inflammatory properties. It is unknown whether that effect also results from melatonin receptor activation, or it is attributed to the modulation of the autonomic nervous system (ANS) activity. Our purpose was to evaluate the effect of MLT and agomelatine (AMT) - melatonin receptor agonist on ANS activity, indirectly assessed by heart rate variability (HRV), in rats with cyclophosphamide-induced hemorrhagic cystitis (CP-HC).

Material and methods: CP-HC was induced in all rats by four doses of cyclophosphamide given intraperitoneally (i.p.) at the dose of $75 \mathrm{mg} / \mathrm{kg} /$ dose Rats were divided on three experimental groups and during induction of cystitis were treated i.p. with: (1) saline (control group); (2A/2B) MTL given at the dose of 40 or $100 \mathrm{mg} / \mathrm{kg} / \mathrm{dose}$; (3A/3B) AMT given at the dose of 40 or $100 \mathrm{mg} / \mathrm{kg} / \mathrm{dose}$. HRV recordings were performed in anesthetized rats at the eight day of the study.

Results: Both $2 \mathrm{~A}$ and $2 \mathrm{~B}$ animals were characterized by an increase in al non-normalized components in HRV spectrum. Furthermore, normalized LF (nLF) increase along with normalized $\mathrm{HF}$ (nHF) decrease were demonstrated in $2 \mathrm{~B}$ rats. AMT treatment resulted only in an increase in total power (TP) and very low frequency (VLF) in $3 \mathrm{~A}$ animals.

Conclusions: $\mathrm{CP}-\mathrm{HC}$ rats treated with MLT were characterized by global ANS activity elevation, with a marked sympathetic tone predominance in subgroup 2B. Since the AMT treatment had no effect on autonomic function, it seems that melatonin modulates autonomic activity via non-receptor mechanisms.

Key words: cyclophosphamide, hemorrhagic cystitis, autonomic nervous system, heart rate variability, melatonin, agomelatine.

Contemp Oncol (Pozn) 2015; 19 (5): 368-373 DOI: $10.5114 /$ wo.2015.52739

\section{Indirect autonomic nervous system activity assessment with heart rate variability in rats with cyclophosphamide-induced hemorrhagic cystitis treated with melatonin or agomelatine}

Łukasz Dobrek, Agnieszka Baranowska, Piotr J. Thor

Department of Pathophysiology, Faculty of Medicine, Jagiellonian University Medical College, Krakow, Poland

\section{Introduction}

Hemorrhagic cystitis ( $\mathrm{HC}$ ), defined as diffuse inflammation of the bladder characterized by hemorrhagic mucosal lesions, is manifested by haematuria and the symptoms of lower urinary tract (LUTS), i.e. dysuria, increased voiding frequency, urinary urgency, nocturia and suprapubic pain [1, 2]. An acute $\mathrm{HC}$ can be caused by both infectious and non-infectious agents, but also its iatrogenic form is recognized in clinical practice as a consequence of chemotherapy with oxazaphosphorine agents, cyclophosphamide (CP) or ifosphamide (IF) [1, 3]. The administration of cyclophosphamide is also associated with the additional risk of myocardial damage, resulting in the development of cardiomyopathy [4]. The pathogenesis of cyclophosphamide- or other oxazaphosphorine-induced $\mathrm{HC}$ is complex; the process is induced by toxic intrabladder metabolite of oxazaphosphorines, acrolein, and finally conditioned by the release of multiple inflammatory mediators, exerting pleiotropic effect on bladder tissues. A more detailed description of CP-HC can be found in one of our previously published papers [5].

The standard prophylactic measures implemented during oxazaphosphorine treatment include intravenous or oral administration of sodium 2-mercaptoethane sulfonate (mesna), which remains the most important uroprotector. That compound inactivates the toxic metabolite, acrolein, released during CP/IF intrabladder biotransformation, to non-toxic thiol derivatives [6]. Moreover, hemostatic preparations are administrated and bladder lavage with saline solution is performed to evacuate clots and maintain diuresis $[2,3]$.

Hemorrhagic cystitis still remains a clinical problem, especially in patients treated with high doses of CP, and the standard procedure mentioned above does not fully prevent from its development. Hence, new prophylactic compounds are tested for their application in the CP-HC prevention. The results of previously published studies point to potential efficacy of intravesically administered diluted potassium aluminium sulphate (an astringent solution), silver nitrate, formalin or phenol (exerting cautering effect), oestrogens (modulating angiogenic processes) or vasopressin (exerting vasoconstriction effect) [7]. Nowadays, melatonin (MLT) is also among the tested agents. MLT is a potent free radical scavenger, antioxidant enzyme activator, a compound inhibiting lipid peroxidation and stabilizer of plasma membranes, which makes them less susceptible to inflammatory damage. Research has also demonstrated anti-inflammatory properties of MLT resulting from down-regulation of pro-inflammatory cytokines and nitric 
oxide inhibition [8]. Melatonin could also alleviate urinary frequency by suppressing the brain micturition centre [9].

However, the pharmacodynamic description of MLT is still incomplete, and it is possible that melatonin is also an agent targeting the autonomic nervous system (ANS), as an additional pharmacological action. Hence, we aimed to determine whether melatonin modulates the ANS function in an experimental CP-HC model, and whether potential changes in autonomic regulation may contribute to its potential uroprotective properties. Moreover, our goal was also to assess the ANS response to agomelatine (AMT), an agonist of MT1/MT2 melatonin receptors with additional antagonistic impact in relation to the receptors $5 \mathrm{HT} 2 \mathrm{C}$, but without additional melatonin-like antioxidant/antiinflammatory properties [10, 11]. Using AMT, we tried to clarify either whether the potential neuromodulating effect of MLT may result from MT receptor activation, or if it is attributed to its additional non-receptor pharmacodynamic mechanisms.

\section{Material and methods}

The medical experiment, which has been described in this paper, was approved by the First Local Ethical Committee for Animal Experiments in Krakow. The experiment was carried out using thirty 11-week-old albino Wistar rats, divided into three groups, ten individuals each. Within 7 days, an experimental cyclophosphamide-induced hemorrhagic cystitis (CP-HC) was evoked in all studied animals, as described previously both Dinis et al. [12] and Chopra et al. [13]. CP-HC developed after four-time (in the first, third, fifth and seventh day of the experiment) intraperitoneal (i.p.) administration of cyclophosphamide, at a dose of $75 \mathrm{mg} / \mathrm{kg}$ b.w. The development of CP-HC was confirmed by histopathological assessment of rats' bladders, obtained at the end of the experiment. Furthermore, we used the same methodology in our previous study, in which the presence of CP-HC-associated bladder overactivity was verified by urodynamic recordings [14].

Group 1 consisted of CP-HC control animals. The animals from other two groups, received i.p. melatonin (group 2) or agomelatine (group 3) 30 minutes after the CP administration. As two animals from the control group died before receiving the last, fourth CP dose, and one rat from group 3 did not complete the whole treatment, eventually these groups consisted of 8 and 9 animals, respectively. All animals from group 2 survived till the end of the study. All studied rats exhibited normal life activity, but their condition and body weight progressively deteriorated due to the adverse, systemic effects of CP.

Due to the use of two doses of both MLT and AMT, groups 2 and 3 were divided into subgroups containing five individuals each: $2 \mathrm{~A}$ or $2 \mathrm{~B}$, and $3 \mathrm{~A}$ or $3 \mathrm{~B}(40 \mathrm{mg} / \mathrm{kg}$ or $100 \mathrm{mg} / \mathrm{kg}$ b.w. MLT or AMT, respectively). Control animals were given i.p. injections of saline instead of MLT/AMT treatment. The choice of MLT/AMT doses was consistent with the other published research (there are reports of MLT and AMT administered at 10-80 mg/kg b.w. and 10-50 mg/ kg b.w., respectively) [15-17]. Hence, we adopted 40 mg/ kg b.w. MLT/AMT as an "average" dose and 100 mg/kg b.w. as a "high" one. Moreover, we also used the same MLT/ AMT high dose in our previous study aimed at assessing the MLT/AMT influence on bladder motility in an experimental model of CP-HC [14]. Melatonin was obtained in crystalline form from Sigma Aldrich, and agomelatine from the commercial preparation Valdoxan ${ }^{\circledR}$, Servier (tablets containing $25 \mathrm{mg}$ AMT). Both MLT and AMT, after preparation of the corresponding doses, were dissolved in water for injection, immediately prior to administration. On the eighth day of the experiment all of the studied animals were subjected to ECG recording, with subsequent analysis of heart rate variability (HRV). The ECG was recorded under general anaesthesia after urethane administration (1200 mg/kg, i.p.) and 20-min rest. Before recordings, the abdominal fur was removed, and the abrasive paste and standard ECG gel were applied. Recordings were collected with the paediatric Ag/AgCl use (EG-S30 PSG Sorimex), deployed in the classic configuration in order to obtain one ECG lead and ADInstruments hardware (Power Lab $4 / 30$ and BIO Amplifier). During registration, the animals remained under a heating lamp to prevent the decline in body temperature. Immediately prior to registration, the animals from subgroups $2 \mathrm{~A} / 2 \mathrm{~B}$ and $3 \mathrm{~A} / 3 \mathrm{~B}$ received the last, fifth MLT/AMT dose, whereas the control rats were given the last injection of saline.

Once registrations were completed, the ECG signal was visually evaluated to remove ectopic beats and the remaining records were subjected to HRV analysis in both time and frequency (spectral) domain, using ADInstruments software (Chart v5.4.2) for Mac OS X Version 10.1.2. The basis for the HRV analysis is the variability of the adjacent, "normal-normal" (N-N) intervals duration, which is subject to continuous, ANS-modulated fluctuations. The other time-domain HRV parameters are secondary measures, based on mean N-N statistical parameters [18]. We analysed standard time-domain HRV parameters: the average duration of $\mathrm{N}-\mathrm{N}$ intervals (mean $\mathrm{N}-\mathrm{N}$ ), the longest $\mathrm{N}-\mathrm{N}$ interval (max $\mathrm{N}-\mathrm{N}$ ), the shortest $\mathrm{N}-\mathrm{N}$ interval (min $\mathrm{N}-\mathrm{N})$, the global standard deviation of N-N intervals (SDN-N), the root mean square of the successive differences (rMSSD) - the successive differences being neighbouring RR intervals (all in [ms]).

During the spectral HRV analysis, total power (TP) of HRV spectrum is determined along with the powers (in $\left[\mathrm{ms}^{2}\right]$ ) of its basic components, i.e. the distribution of $\mathrm{N}-\mathrm{N}$ intervals with respect to the cyclic ANS-modulated activity of the sinus node, associated with three main essential rhythms: in the range of very low (VLF), low (LF) and high (HF) frequencies [18]. In this analysis, we adopted the following ranges for the individual spectral components of HRV: $0.18<$ VLF $<0.28<L F<0.78<H F<3$. These frequency ranges were similar to those used by Aubert et al. [19] $(0.19<\mathrm{LF}<0.74<\mathrm{HF}<2.5)$, and Goncalves et al. [20] $(0.10<\mathrm{LF}<1.0<\mathrm{HF}<3.0)$. Subjecting the the HRV spectrum to the process of normalization, we also calculated the normalized $n \mathrm{HF}$ and $\mathrm{nLF}$ values, which are regarded to reflect the selective parasympathetic and sympathetic tension, respectively. The HRV spectrum normalization is based on the calculation of the sharing of relevant com- 
ponents (LF or HF) in total HRV power, excluding VLF component power. This procedure results from the difficulties of interpretation regarding the VLF component [18, 21, 22] (see below in Discussion section).

Finally, after the administration of the lethal dose of sodium pentobarbital (400 mg/kg b.w.), a cystectomy was performed to measure the bladder wet weight (BWW) and to obtain specimens for histopathological evaluation. A bladder was collected from each of the study animals, following a previous separation from the surrounding adipose tissue and voiding. According to literature, BWW may be considered an indirect measure of inflammatory remodelling of the bladder $[23,24]$. Immediately after collection, bladders were weighed on an analytic scale and then placed in 4\% formalin solution with PBS for further histopathological evaluation. The finally prepared microscopic sections were stained with hematoxylin and eosin $(\mathrm{HE})$ to enable the histologic evaluation of the inflammation severity.

The HRV results were expressed as mean \pm SD. Statistical analysis was performed using analysis of variance (ANOVA), which verifies the existence of statistically significant differences between three studied populations. Whenever statistically significant differences were demonstrated $(p<0.05$ on ANOVA test), the significance of differences between paired (1-2A, 1-2B, 1-3A and 1-3B) populations was tested using the Student's t-test. All statistical calculations were performed on values subjected to logarithmic transformation in order to ensure greater consistency of analysed HRV parameters with normal distribution.

\section{Results}

\section{Characteristics of the studied groups}

In all analysed groups, a progressive decrease in body weight, associated with the subsequent doses of the CP, was noted. On the 7th day of the experiment, the animals from subgroup 2B were characterized by the lowest body weight, while the control group by the highest one. A similar dependence was found in the case of mean body weight for all studied groups. However, these differences were not statistically significant. Detailed data are provided in Table 1.

\section{Assessment of the collected bladders}

Bladder wet weight measurement showed that the animals treated with MLT (subgroup 2A and 2B) were characterized by slightly higher BWW values compared to animals treated with AMT (subgroups $3 \mathrm{~A}$ and $3 \mathrm{~B}$ ) and to the controls. These differences were not statistically significant. The detailed results are also given in Table 1 . The histopathological examination of bladder specimens confirmed the presence of inflammatory lesions in all studied groups.

Bladders collected from control rats were characterized by a clear oedema and signs of congestion (mostly in the mucosa), along with signs of focal proliferation of fibroblasts in the mucosal lamina propria, mostly around some fine submucosal blood extravasations. Fine lymphocytic inflammatory infiltrations were visible in the vicinity of vessels of the mucosal lamina propria. Epithelium of the bladder lining demonstrated focal ulceration with signs of clear proliferation of cells. Complex papillary architecture showing anastomosis of papillae with focally irregular nuclei and few scattered mitotic figures was intensified in subgroups $3 \mathrm{~A} / 3 \mathrm{~B}$, while signs of oedema and hyperaemia were revealed in subgroups $2 \mathrm{~A} / 2 \mathrm{~B}$ (MLT treatment) and in the controls; the lesions documented in subgroups $2 \mathrm{~A} / 2 \mathrm{~B}$ was slightly lower than in the controls.

\section{Results of HRV analysis \\ Time-domain HRV analysis}

The animals treated with MLT, regardless of the MLT dose, were characterized by the highest values of mean and maximum N-N interval, with concurrently the lowest value of min $\mathrm{N}-\mathrm{N}$ from all groups. The differences related to mean N-N were statistically significant. Additionally, rats from subgroups $2 \mathrm{~A}$ and $2 \mathrm{~B}$ were characterized by the lowest average heart rate, and the highest SDN-N and rMSSD values. These differences turned out to be statistically significant when compared to the controls. Most of the time-domain HRV parameters recorded in AMT-treated animals did not differ significantly from respective values of the controls, except for the average HR and rMSSD (these parameters were significantly lower) and mean N-N (it was higher) in animals from subgroup $3 \mathrm{~A}$ and average

Table 1. The body weight $[\mathrm{g}]$ and bladder wet weight (BWW) $[\mathrm{mg}]$ of the studied animals (mean \pm SD)

\begin{tabular}{|c|c|c|c|c|c|c|}
\hline & \multicolumn{5}{|c|}{ Body weight } & \multirow[t]{2}{*}{ BWW } \\
\hline & $1^{\text {st }}$ day $-1^{\text {st }}$ dose & $3^{\text {rd day }}-2^{\text {nd }}$ dose & $5^{\text {th }}$ day $-3^{\text {rd }}$ dose & $7^{\text {th }}$ day $-4^{\text {th }}$ dose & Mean body weight & \\
\hline $\begin{array}{l}\text { Group } 1 \\
\text { Control }\end{array}$ & $288.0 \pm 11.8$ & $284.5 \pm 9.1$ & $283.7 \pm 9.4$ & $281.7 \pm 10.6$ & $284.5 \pm 3.6$ & $181.9 \pm 4.6$ \\
\hline $\begin{array}{l}\text { Subgroup 2A } \\
\text { CP-HC + MLT } 40\end{array}$ & $286.7 \pm 16.6$ & $284.7 \pm 28.0$ & $273.7 \pm 26.9$ & $258.7 \pm 23.6$ & $275.9 \pm 12.8$ & $191.7 \pm 5.4$ \\
\hline $\begin{array}{l}\text { Subgroup 2B } \\
\text { CP-HC + MLT } 100\end{array}$ & $274.7 \pm 16.2$ & $268.0 \pm 10.4$ & $260.0 \pm 8.7$ & $246.0 \pm 9.9$ & $262.2 \pm 12.3$ & $209.6 \pm 6.1$ \\
\hline $\begin{array}{l}\text { Subgroup 3A } \\
\text { CP-HC + AMT } 40\end{array}$ & $281.3 \pm 8.1$ & $278.0 \pm 6.9$ & $272.0 \pm 8.7$ & $256.3 \pm 3.8$ & $271.9 \pm 11.1$ & $184.6 \pm 4.4$ \\
\hline $\begin{array}{l}\text { Subgroup 3B } \\
\text { CP-HC + AMT } 100\end{array}$ & $279.7 \pm 13.3$ & $279.3 \pm 16.7$ & $276.7 \pm 16.3$ & $267.3 \pm 13.6$ & $275.8 \pm 5.7$ & $192.1 \pm 4.3$ \\
\hline
\end{tabular}


Table 2. Time-domain HRV analysis results (mean \pm SD; NS - non-significant). Statistical analysis performed for logarithmic values

\begin{tabular}{|c|c|c|c|c|c|}
\hline \multirow[t]{2}{*}{ Parameter } & \multirow{2}{*}{$\begin{array}{l}\text { Group } 1 \\
\text { Control }\end{array}$} & \multirow{2}{*}{$\begin{array}{l}\text { Subgroup 2A } \\
\text { MLT } 40 \mathrm{mg} / \mathrm{kg}\end{array}$} & \multirow{2}{*}{$\begin{array}{l}\text { Subgroup 3A } \\
\text { AMT } 40 \mathrm{mg} / \mathrm{kg}\end{array}$} & \multicolumn{2}{|c|}{ Statistic $p$ value } \\
\hline & & & & $1-2 \mathrm{~A}$ & $1-3 A$ \\
\hline mean N-N [ms] & $160.7 \pm 9.9$ & $171.2 \pm 11.3$ & $170.6 \pm 7.2$ & 0.05 & 0.02 \\
\hline $\max N-\mathrm{N}[\mathrm{ms}]$ & $182.6 \pm 6.9$ & $188.9 \pm 3.1$ & $187.1 \pm 1.2$ & NS & NS \\
\hline $\min \mathrm{N}-\mathrm{N}[\mathrm{ms}]$ & $146.2 \pm 8.3$ & $141.7 \pm 4.4$ & $147.1 \pm 9.7$ & NS & NS \\
\hline average HR [1/min] & $375.3 \pm 23.0$ & $350.7 \pm 22.8$ & $352.4 \pm 15.5$ & 0.04 & 0.01 \\
\hline SD N-N [ms] & $6.2 \pm 2.3$ & $11.2 \pm 4.5$ & $8.6 \pm 3.6$ & 0.02 & NS \\
\hline rMSSD [ms] & $4.1 \pm 4.2$ & $9.4 \pm 8.6$ & $1.4 \pm 1.8$ & 0.05 & 0.05 \\
\hline \multirow[t]{2}{*}{ Parameter } & Group 1 & Subgroup 2B & Subgroup 3B & \multicolumn{2}{|c|}{ Statistic $p$ value } \\
\hline & Control & MLT $100 \mathrm{mg} / \mathrm{kg}$ & AMT $100 \mathrm{mg} / \mathrm{kg}$ & $1-2 B$ & $1-3 B$ \\
\hline mean N-N [ms] & $160.7 \pm 9.9$ & $175.8 \pm 9.6$ & $167.7 \pm 5.2$ & 0.01 & NS \\
\hline $\max N-\mathrm{N}[\mathrm{ms}]$ & $182.6 \pm 6.9$ & $188.8 \pm 5.5$ & $184.9 \pm 7.0$ & NS & NS \\
\hline $\min \mathrm{N}-\mathrm{N}[\mathrm{ms}]$ & $146.2 \pm 8.3$ & $147.9 \pm 12.8$ & $149.7 \pm 11.2$ & NS & NS \\
\hline average HR [1/min] & $375.3 \pm 23.0$ & $342.2 \pm 18.9$ & $358.0 \pm 11.0$ & 0.01 & 0.03 \\
\hline SD N-N [ms] & $6.2 \pm 2.3$ & $10.1 \pm 5.2$ & $5.5 \pm 2.5$ & 0.04 & NS \\
\hline rMSSD [ms] & $4.1 \pm 4.2$ & $10.9 \pm 8.5$ & $5.2 \pm 4.3$ & 0.03 & NS \\
\hline
\end{tabular}

HR (lower value) in rats from subgroup 3B. Detailed results of the time-domain HRV parameters, including statistical conclusions, are presented in Table 2.

\section{Spectral (frequency) HRV analysis}

The spectral analysis carried out in MLT-treated animals revealed statistically significant differences for the total power value of the HRV spectrum, and for all non-normalized parameters: VLF, LF and HF. They achieved significantly higher values in animals treated with MLT, at both $40 \mathrm{mg} /$ kg b.w. (subgroup 2A) and $100 \mathrm{mg} / \mathrm{kg}$ b.w. (subgroup 2B), than in the controls. These differences were more pronounced in subgroup 2B, i.e. after higher MLT dose. Furthermore, the animals of this subgroup differed significantly from the controls in terms of the normalized parameters, namely higher nLF and lower nHF. A similar phenomenon was not observed in subgroup 2A, i.e. after the smaller MLT dose.

Contrary to the rats treated with MLT, animals treated with AMT did not differ significantly from the controls in terms of spectral parameters of HRV, with the exception of TP and VLF, which achieved significantly higher values in rats treated with AMT at $40 \mathrm{mg} / \mathrm{kg}$ b.w. The detailed results of HRV spectral analysis, including statistical conclusions, are presented in Table 3.

\section{Discussion}

Our most important finding in the analysis of HRV in animals with experimental, cyclophosphamide-induced hemorrhagic cystitis, treated with either melatonin or agomelatine, was to demonstrate that:

1. Melatonin, administered in rats with cyclophosphamide-induced cystitis, modulated ANS activity, causing an increase in global autonomic tension. The agent either proportionally stimulated both sympathetic and parasympathetic part of ANS (at a dose of $40 \mathrm{mg} / \mathrm{kg}$ b.w.) or preferentially enhanced sympathetic activity (at a dose of $100 \mathrm{mg} / \mathrm{kg}$ b.w.).
2. Agomelatine, regardless of the applied dose, did not exert significant effect on autonomic activity in animals with cyclophosphamide-induced cystitis.

3. Taking into account the fact that AMT, as melatonin receptors agonist, did not affect the functional autonomic state, it may be assumed that the modulatory effect of MLT on the ANS activity seems to result from its non-receptor pharmacodynamic mechanisms (e.g. antioxidant activity, regulating the secretion of various inflammatory mediators).

Currently, the indirect, non-invasive assessment of the autonomic nervous system activity enables the analysis of heart rate variability (HRV). The stimulation of sympathetic or parasympathetic ANS branch is reflected by changes in the HRV parameters, both time- and spectral ones. According to the commonly accepted interpretative HRV guidelines [18, 21, 22, 25], parameters such as SDN-N and nLF correlate with sympathetic activity, rMSSD, HF and $\mathrm{nHF}$ are associated with parasympathetic activity, and the power of LF component reflects the activity of both the sympathetic and parasympathetic part. Total power (TP) of the HRV spectrum is a marker of the global ANS activity.

The interpretation of the part of the HRV spectrum attributing to the range of very low frequency (VLF) is the most controversial. The exact mechanisms underlying the formation of that spectral component of HRV are still not completely understood. The background of VLF includes a broad array of various stimuli: thermoregulatory processes, the renin-angiotensin-aldosterone system, haemodynamics feedback delays, mechanical and central neuronal effects of breathing patterns, spinal reflexes or vascular autorhythmicity [26]. The VLF power increases during sympathetic stimulation (systemic stress, chronic heart failure, shock, vasodilatation). On the other hand, some evidence suggests that VLF may be of parasympathetic origin. Taylor et al. [27] showed that atropine almost completely abolished VLF power and other spectral components. Silva Soares et al. [28] also revealed that 
Table 3. Spectral-domain HRV analysis results (mean \pm SD; NS - non-significant). Statistical analysis performed for logarithmic values

\begin{tabular}{|c|c|c|c|c|c|}
\hline \multirow[t]{2}{*}{ Parameter } & \multirow{2}{*}{$\begin{array}{l}\text { Group } 1 \\
\text { Control }\end{array}$} & \multirow{2}{*}{$\begin{array}{l}\text { Subgroup 2A } \\
\text { MLT } 40 \mathrm{mg} / \mathrm{kg}\end{array}$} & \multirow{2}{*}{$\begin{array}{l}\text { Subgroup 3A } \\
\text { AMT } 40 \mathrm{mg} / \mathrm{kg}\end{array}$} & \multicolumn{2}{|c|}{ Statistic $p$ value } \\
\hline & & & & $1-2 A$ & $1-3 A$ \\
\hline $\mathrm{TP}\left[\mathrm{ms}^{2}\right]$ & $11.1 \pm 14.1$ & $49.5 \pm 53.5$ & $19.6 \pm 6.9$ & 0.05 & 0.01 \\
\hline $\operatorname{VLF}\left[\mathrm{ms}^{2}\right]$ & $7.4 \pm 8.7$ & $39.1 \pm 45.2$ & $17.2 \pm 6.9$ & 0.05 & 0.01 \\
\hline $\operatorname{LF}\left[\mathrm{ms}^{2}\right]$ & $1.4 \pm 2.1$ & $5.5 \pm 5.8$ & $1.2 \pm 1.1$ & 0.05 & NS \\
\hline $\mathrm{HF}\left[\mathrm{ms}^{2}\right]$ & $2.4 \pm 3.5$ & $4.9 \pm 4.1$ & $1.3 \pm 1.2$ & 0.04 & NS \\
\hline$n L F[n . u]$. & $40.0 \pm 20.6$ & $40.9 \pm 18.9$ & $37.7 \pm 26.0$ & NS & NS \\
\hline nHF [n.u.] & $60.0 \pm 20.5$ & $59.1 \pm 18.9$ & $62.3 \pm 26.0$ & NS & NS \\
\hline \multirow[t]{2}{*}{ Parameter } & Group 1 & Subgroup 2B & Subgroup 3B & \multicolumn{2}{|c|}{ Statistic $p$ value } \\
\hline & Control & MLT $100 \mathrm{mg} / \mathrm{kg}$ & АMT $100 \mathrm{mg} / \mathrm{kg}$ & $1-2 B$ & $1-3 B$ \\
\hline $\mathrm{TP}\left[\mathrm{ms}^{2}\right]$ & $11.1 \pm 14.1$ & $58.6 \pm 47.1$ & $17.8 \pm 20.3$ & 0.01 & NS \\
\hline $\operatorname{VLF}\left[\mathrm{ms}^{2}\right]$ & $7.4 \pm 8.7$ & $47.3 \pm 38.2$ & $11.0 \pm 15.3$ & 0.01 & NS \\
\hline$L F\left[\mathrm{~ms}^{2}\right]$ & $1.4 \pm 2.1$ & $6.2 \pm 5.4$ & $1.8 \pm 2.7$ & 0.02 & NS \\
\hline $\mathrm{HF}\left[\mathrm{ms}^{2}\right]$ & $2.4 \pm 3.5$ & $5.1 \pm 4.3$ & $4.9 \pm 8.0$ & 0.03 & NS \\
\hline$n L F[n . u]$. & $40.0 \pm 20.6$ & $55.9 \pm 5.9$ & $32.2 \pm 20.4$ & 0.04 & NS \\
\hline nHF [n.u.] & $60.0 \pm 20.5$ & $44.1 \pm 5.9$ & $67.8 \pm 20.4$ & 0.03 & NS \\
\hline
\end{tabular}

VLF band may be driven by parasympathetic modulation. They demonstrated that stimulation with pyridostigmine (reversible cholinesterase inhibitor) produced a strong increase in VLF power. Therefore, VLF may also depend on the presence of parasympathetic outflow.

Having taken into account the abovementioned interpretative HRV guidelines, the results of our experiment support the hypothesis that the administration of melatonin in $\mathrm{CP}-\mathrm{HC}$ rats produces modulatory effect in relation to the ANS activity, the more pronounced the higher MLT dose was applied. Administration of MLT (100 mg/kg b.w., subgroup 2B) was reflected by evident sympathetic predominance. This was manifested by an increase in SDN-N and $\mathrm{nLF}$ and, indirectly, by an increase in VLF and LF (assuming sympathetic background of these two parameters).

Contrary to MLT therapy, administration of agomelatine did not result in any significant changes in both the global autonomic activity and tones of its particular parts. As mentioned above, agomelatine is a melatonin receptor agonist. Therefore, it may be assumed that modulatory properties of MLT did not result from the MT1/2 receptor stimulation, but rather from non-receptor, additional pharmacodynamic mechanisms of MLT, related to the antioxidant and inflammation-regulatory properties of this agent. The stimulation of the sympathetic part after MLT treatment can also result in amelioration of the adrenergic-mediated (via receptors) bladder overactivity (CP-HC is associated with some LUTS originating from bladder over-contractility).

The abovementioned findings, pointing to a role of MLT in the regulation of the autonomic function in $\mathrm{CP}-\mathrm{HC}$, are also consistent with the results of our previous studies which evaluated influence of MLT and AMT on bladder motility in an experimental CP-HC model [14]. We revealed that MLT (75 or $100 \mathrm{mg} / \mathrm{kg}$ b.w.) ameliorated bladder overactivity observed in the course of experimental CP-HC. On the contrary, AMT applied at the same dose, even aggra- vated dysfunction of bladder contractility, as documented on urodynamic recordings. Thus, we showed for the first time that the improvement in bladder over-contractility after MLT administration may be due to its additional, antioxidative and anti-inflammatory properties and is not related to MT receptor activation [14].

The beneficial role of MLT, as an antioxidant compound used in the CP-HC, was also confirmed by Topal et al. [29]. They showed that melatonin exerted significant protective effect against CP-induced cystitis by diminishing bladder oxidative stress and blocking inducible nitric oxide synthase and peroxynitrite production. They also postulated that oxidants may play a major role in the pathogenesis of CP-HC, and thus MLT seems to be one of the new, most promising candidates to ameliorate bladder damage induced by CP. The findings of Topal et al. were confirmed by Sadir et al. [30] who also demonstrated that $\alpha$-tocopherol and melatonin show meaningful protective effect against bladder damage in CP-HC rats. More detailed study aimed to assess MLT influence on bladder inflammatory process in CP-HC model was performed by Zhang et al. [31]. They analysed the expressions of heme oxygenase-1 (HO-1), inducible nitric oxide synthase (iNOS) and substance P (SP), and demonstrated that melatonin significantly attenuated bladder symptoms and histological damage in CP-HC rats by diminishing bladder oxidative stress, blocking iNOS, up-regulating $\mathrm{HO}-1$, and down-regulating the expression of SP. On a margin, the beneficial effect of MLT on bladder injury was also revealed in other than CP-induced models. Cetinel et al. [32] investigated the effects of melatonin on protamine sulphate-induced bladder injury and demonstrated that bladder malondialdehyde level was decreased in MLT-treated rats.

To summarize, there are some reports indicating that antioxidative and anti-inflammatory features of MLT may result in attenuation of a CP-induced bladder injury. Our study confirmed once again the non-receptor nature of the potential, uroprotective effects exerted by MLT in CP-HC, 
and showed that the beneficial effects of this compound may be partially caused by the reorganization of the ANS status with the sympathovagal balance shifted towards sympathetic overdrive. The increased sympathetic function and global autonomic tension, observed in experimental CP-HC after a large MLT dose, improve bladder compliance and can contribute to alleviating of some LUTS resulting from bladder overactivity. Our findings, as well as the results of the abovementioned previous studies, justify further research on the beneficial role of MLT in the CP-HC. The future studies may lead to official approval of MLT as yet another new uroprotector reducing the toxicity of cyclophosphamide.

\section{The authors declare no conflict of interest.}

\section{References}

1. Ribeiro RA, Lima-Junior RCP, Leite CAVG, Mota JMSC, Macedo FYB, Lima MVA, Brito GAC. Chemiotherapy-induced hemorrhagic cystitis: pathogenesis, pharmacological approaches and new insights. J Exp Integr Med 2012; 2: 95-112.

2. Manikandan R, Kumar S, Dorairajan LN. Hemorrhagic cystitis: a challenge to the urologist. Indian J Urol 2010; 26: 159-66.

3. Altayli E, Malkoc E, Alp BF, Korkmaz A. Prevention and treatment of cyclophosphamide and ifosfamide-induced hemorrhagic cystitis J Mol Pathophysiol 2012; 1: 53-62.

4. Dhesi S, Chu MP, Blevins G, Paterson I, Larratt L, Oudit GY, Kim $\mathrm{DH}$. Cyclophosphamide-induced cardiomyopathy: a case report, review and recommendations for management. JIM High Impact Case Reports 2013; 1: 1-7.

5. Dobrek $七$, Thor P. Bladder urotoxicity pathophysiology induced by oxazaphosphorine alkylating agents and its chemoprevention. Postepy Hig Med Dosw (online) 2012; 66: 592-602.

6. Ścieszka M, Kamińska-Budzińska G, Machalski M, Kozaczka A. Leki cytoprotekcyjne w chemioterapii nowotworów. Współczesna Onkol 2001; 5: 62-9.

7. West J. Prevention and treatment of hemorrhagic cystitis. Pharmacotherapy 1997; 17: 696-706.

8. No Authors listed. Melatonin. Monograph. Altern Med Rev 2005; 10: 326-36.

9. Pozo MJ, Gomez-Pinilla PJ, Camello-Almaraz C, Martin-Cano FE, Pascua P, Rol MA, Acuna-Castroviejo D, Camello PJ. Melatonin, a potential therapeutic agent for smooth muscle-related pathological conditions and aging. Curr Med Chem 2010; 17: 4150-65.

10. Girish MB, Bhuvana K, Nagesh Raju G, Sarala N. A novel atypical antidepressant drug: Agomelatine - A review. Int J Pharm Biomed Res 2010; 1: 113-16.

11. De Berardis D, Conti C, Marini S, et al. Is there a role for agomelatine in the treatment of anxiety disorders? A review of published data. Int J Immunopathol Pharmacol 2013; 26: 299-304.

12. Dinis P, Charrua A, Avelino A, Cruz F. Intravesical resiniferatoxin de creases spinal c-fos expression and increases bladder volume to reflex micturition in rats with chronic inflamed urinary bladders. BJU Int 2004; 94: 153-7.

13. Chopra B, Barrick SR, Meyers S, Beckel JM, , Zeidel ML, Ford APDW, De Groat WC, Birder LA. Expression and function of bradykinin $B 1$ and $B 2$ receptors in normal and inflamed rat urinary bladder urothelium. J Physiol 2005; 562 (Pt 3): 859-71.

14. Dobrek $t$, Thor PJ: The influence of melatonin and agomelatine on urodynamic parameters in experimental overactive bladder model - preliminary results. Postepy Hig Med Dosw (online) 2011; 65: 725-33.

15. Loiseau F, Le Bihan C, Hamon M, Thiebot MH. Effects of melatonin and agomelatine in anxiety-related procedures in rats: interaction with diazepam. Eur Neuropsychopharmacol 2006; 16: 417-28.
16. Norman TR, Cranston I, Irons JA, Gabriel C, Dekeyne A, Millan MM, Mocaer E. Agomelatine suppresses locomotor hyperactivity in olfactory bulbectomised rats: a comparison to melatonin and to the 5-HT2c antagonist, S32006. Eur J Pharmacol 2012; 674: 27-32.

17. Descamps A, Rousset C, Dugua H, Debilly G, Delagrange P, Cespuglio R. Agomelatine restores a physiological response to stress in the aged rat. Neurosci Lett 2014; 566: 257-62.

18. Malik M (ed.). Heart rate variability. Standards of measurement, physiological interpretation, and clinical use. Task Force of The European Society of Cardiology and The North American Society of Pacing and Electrophysiology. Eur Heart J 1996; 17: 354-81.

19. Aubert AE, Ramaekers D, Beckers F, Breem R, Denef C, Van De Werf $F$, Ector $H$. The analysis of heart rate variability in unrestrained rats. Validation of method and results. Comput Methods Programs Biomed 1999; 60: 197-213.

20. Goncalves H, Henriques-Coelho T, Bernardes J, Rocha AP, BrandaoNogueira A, Leite-Moreira A. Analysis of heart rate variability in a rat model of induced pulmonary hypertension. Med Eng Phys 2010; 32: 746-52.

21. Stauss HM. Heart rate variability. Am J Physiol Regul Integr Comp Physiol 2003; 285: R927-R931.

22. Pumprla J, Howorka K, Groves D, Chester M, Nolan J. Functional assessment of heart rate variability: physiological basis and practical applications. Int J Cardiol 2002; 84: 1-14.

23. Schroder A, Newgreen D, Andersson KE. Detrusor responses to prostaglandin e2 and bladder outlet obstruction in wild-type and ep1 receptor knockout mice. J Urol 2004; 172: 1166-70.

24. Zeng J, Pan C, Jiang C, Lindstrom S. Cause of residual urine in bladder outlet obstruction: an experimental study in the rat. J Urol 2012; 188: 1027-32

25. Sztajzel J. Heart rate variability: a noninvasive electrocardiographic method to measure the autonomic nervous system. Swiss Med Wkly 2004; 134: 514-22.

26. Berntson GG, Bigger JT JR, Eckberg DL, et al. Heart rate variability: origins, methods, and interpretive caveats. Psychophysiology 1997; 34: 623-48

27. Taylor JA, Carr DL, Myers CW, Eckberg DL. Mechanisms underlying very low frequency RR-interval oscillations in humans. Circulation 1998; 98: 547-55.

28. Silva Soares $P$, da Nobrega ACL, Ushizima MR, Irigoyen MCC. Cholinergic stimulation with piridostigmine increases heart rate variability and baroreflex sensivity in rats. Auton Neurosci 2004; 113: 24-31.

29. Topal T, Oztas Y, Korkmaz A, Sadir S, Oter S, Coskun O, Bilgic H. Melatonin ameliorates bladder damage induced by cyclophosphamide in rats. J Pineal Res 2005; 38: 272-77.

30. Sadir S, Deveci S, Korkmaz A, Oter S. Alpha-tocopherol, beta-carotene and melatonin administration protects cyclophosphamide-induced oxidative damage to bladder tissue in rats. Cell Biochem Funct 2007; 25: 521-26.

31. Zhang Q, Zhou Z, Lu G, Song B, Guo J. Melatonin improves bladder symptoms and may ameliorate bladder damage via increasing HO-1 in rats. Inflammation 2013; 36: 651-7.

32. Cetinel S, Ercan F, Sirvanci S, Sehirli O, Ersoy Y, San T, Sener G. The ameliorating effect of melatonin on protamine sulfate induced bladder injury and its relationship to interstitial cystitis. J Urol 2003; 169: 1564-68.

\section{Address for correspondence}

Łukasz Dobrek, MD PhD

Department of Pathophysiology

Jagiellonian University Medical College

Czysta 18

31-121 Krakow, Poland

tel./fax 126329056

e-mail: lukaszd@mp.pl

Submitted: 30.06 .2014

Accepted: $\quad 27.05 .2015$ 